Theologische Realenzyklopädie Band XIV

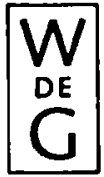





\title{
Theologische Realenzyklopädie
}

\author{
In Gemeinschaft mit \\ Horst Robert Balz - Stuart G. Hall \\ Brian L. Hebblethwaite - Richard Hentschke \\ Wolfgang Janke - Günter Lanczkowski \\ Joachim Mehlhausen - Carl Heinz Ratschow \\ Knut Schäferdiek · Henning Schröer \\ Gottfried Seebaß · Clemens Thoma \\ herausgegeben von \\ Gerhard Müller
}

Band XIV
Gottesdienst - Heimat

Walter de Gruyter - Berlin - New York 1985 


\section{Redaktion: Dr. Christian Uhlig}

Lieferung 1/2 Gottesdienst - Häresie ersch. August 1985

Lieferung 3/4 Häresie - Heiler ersch. Dezember 1985

Lieferung 5 Heiler - Heimat ersch. Dezember 1985

CIP-Kurztitelaufnahme der Deutschen Bibliothek

Theologische Realenzyklopädie / in Gemeinschaft mit Horst Robert Balz ... hrsg. von Gerhard Müller. - Berlin ; New York : de Gruyter.

Teilw. hrsg. von Gerhard Krause u. Gerhard Müller

NE: Krause, Gerhard [Hrsg.]; Müller, Gerhard [Hrsg.]

Bd. 14. Gottesdienst - Heimat. - 1985.

Abschlußaufnahme von Bd. 14

ISBN 3-11-008583-6

(C) 1985 by Walter de Gruyter \& Co.

Alle Rechte, insbesondere das Recht der Vervielfältigung und Verbreitung sowie der Übersetzung, vorbehalten. Kein Teil des Werkes darf in irgendeiner Form (durch Photokopie, Mikrofilm oder ein anderes Verfahren) ohne schriftliche Genehmigung des Verlages reproduziert werden.

Printed in Germany.

Satz und Druck: Tutte Druckerei GmbH, Salzweg-Passau

Bindearbeiten: Lüderitz \& Bauer, Berlin 61 